\title{
Locomotor activity of Drosophila melanogaster in high temperature environments: plastic and evolutionary responses
}

\author{
Anders Kjærsgaard ${ }^{1, *}$, Ditte Demontis ${ }^{1,2}$, Torsten Nygaard Kristensen ${ }^{1,3}{ }^{,}$Nguyet Le $^{1}$, \\ Søren Faurby ${ }^{1}$, Cino Pertoldi ${ }^{1,4}{ }^{,}$Jesper Givskov Sørensen ${ }^{5}$, Volker Loeschcke ${ }^{1}$ \\ ${ }^{1}$ Ecology and Genetics, Department of Biological Sciences, Aarhus University, Ny Munkegade 114, 8000 Aarhus C, Denmark \\ ${ }^{2}$ Department of Human Genetics, Faculty of Health Sciences, Aarhus University, Wilhelm Meyers Allé 4, 8000 Aarhus C, Denmark \\ ${ }^{3}$ Department of Genetics and Biotechnology, Danish Institute of Agricultural Sciences, Blichers Allé 20, 8830 Tjele, Denmark \\ ${ }^{4}$ Mammal Research Institute, Polish Academy of Sciences, Waszkiewicza 1c, 17-230 Białowieża, Poland \\ ${ }^{5}$ National Environmental Research Institute, Aarhus University, Department of Terrestrial Ecology, Vejlsøvej 25, \\ PO Box 314, 8600 Silkeborg, Denmark
}

\begin{abstract}
Regular exposure to a given stressor poses selective pressure towards increased resistance. In high temperature environments this can be mediated through physiological and biochemical adjustments that lead to increased resistance to heat coma. Such adjustments may influence complex traits such as locomotor activity through cascading effects. Alternatively, changes in locomotor activity may change the exposure to the stressor and, thereby, the importance of the physiological and biochemical adjustments. In this experiment we analysed how selection for heat shock resistance may affect locomotor activity at high temperatures in Drosophila melanogaster. We compared 2 lines selected for heat shock (HS) and cold shock (CS) resistance at 4 constant high temperatures (28 to $38^{\circ} \mathrm{C}$ ). We also tested the importance of heat shock protein (Hsp) expression by comparing locomotor activity at the same temperatures of a heat-sensitive mutant line $\left(\mathrm{Hsf}^{0}\right)$, where the heat shock factor (Hsf) is non-functional at high temperatures, with that of a rescued mutant line $\left(\mathrm{Hsf}^{+}\right)$with a functional Hsf re-inserted. At moderately stressful temperatures $\left(28\right.$ and $\left.34^{\circ} \mathrm{C}\right)$, flies from the $\mathrm{Hsf}^{0}$ line were more active than flies from the $\mathrm{Hsf}^{+}$line, whereas this was reversed at higher temperatures. In the selection lines, the CS flies were more active at $28^{\circ} \mathrm{C}$ but this was reversed at 34 and $36^{\circ} \mathrm{C}$, whereas no difference was observed at the most stressful temperature $\left(38^{\circ} \mathrm{C}\right)$. This suggests that the lines selected for increased cold tolerance were more stressed at moderately high temperatures and, therefore, more active in the attempt to escape the stress, whereas at higher temperatures, their locomotor activity was more compromised than in flies from the lines selected for increased heat resistance.
\end{abstract}

KEY WORDS: Thermal selection - Environmental stress - Heat resistance - Heat shock factor · Climate change

Resale or republication not permitted without written consent of the publisher

\section{INTRODUCTION}

One major challenge in evolutionary biology is to obtain a better understanding of traits of importance for fitness (Roff 2002). Fitness estimates of populations in different environments are often based on life history traits and/or body size. Less attention has been devoted to behavioural traits that are important for the ability to disperse, compete and search for food, avoid stressful environmental conditions and find or compete for mates (Dukas 2004, Dingemanse et al. 2010). This is probably because it can be difficult to evaluate the outcomes of particular behaviours in terms of fitness and it is often laborious to quantify behavioural traits (Martin 2003).

The ability to sustain behavioural activities in high temperature environments relies on the underlying 
traits and their organisation (Feder 1996). Environmental change can alter the association of traits (Kjærsgaard et al. 2007) and thus the phenotype which can modify behaviour or locomotor activity (Valente et al. 2007, Bettencourt et al. 2009, Dillon et al. 2009). This may have consequences for mortality rates and lifetime reproductive success, more so in light of current climatic changes where the capacity to cope with higher temperature is of central importance to the survival of species.

While most studies report on adaptation to regional average temperatures, the actual temperatures experienced by the organisms may not reflect this, especially if some aspect of the microhabitat allows thermal buffering through behavioural adjustments (Kennedy 1997, Huey et al. 2003). It is, however, increasingly recognised that high variance in temperatures, and particularly extreme temperatures, experienced by an organism can have a much larger impact on the phenotype than more homogeneous temperature regimes close to the average temperature (Ruel \& Ayres 1999, Bahrndorff et al. 2009, Kingsolver et al. 2009, Rego et al. 2010). Therefore, it is essential to investigate species performances at the borders of their physiological limits; this may provide important insights into rangelimiting factors (Lee et al. 2009, Chown et al. 2010, this Special) as well as the capacity to cope with climatic change (Byars \& Hoffmann 2009). Temperature is probably the most important extrinsic factor in this respect for ectotherms as it influences nearly all ratedependent processes from biochemical kinetics to life history traits (Cossins \& Bowler 1987, Hochachka \& Somero 2002).

In the present study we used a simple methodology to estimate locomotor activity in high-temperature environments. Locomotor activity of an individual has been suggested to be a good indicator of the overall physiological state of an individual and thus constitutes an important component of fitness (Fleury et al. 2000, Gibert et al. 2001). The capacity to remain active in stressful environments is potentially adaptive as individuals that are better able to withstand the stressor can allocate more time to different behavioural activities (Dahlgaard et al. 2001, Fasolo \& Krebs 2004).

In this experiment, lines expected to differ in thermal tolerance were scored automatically and simultaneously for locomotor activity in individual test tubes at several stressful high temperatures. Two pairs of lines of Drosophila melanogaster with contrasting genetic constitutions were used in the experiments. One pair consisted of lines selected for heat shock (HS) and cold shock (CS) resistance, respectively. The other pair consisted of a heat shock factor (Hsf) line $\left(\mathrm{Hsf}^{0}\right)$ which has a very limited capacity to induce heat shock proteins (Hsps) at temperatures above $30^{\circ} \mathrm{C}$ and another line
$\left(\mathrm{Hsf}^{+}\right)$which has been rescued by insertion of a functional hsf gene. The capacity of $\mathrm{Hsf}^{0}$ to induce Hsps gradually increases at temperatures below $30^{\circ} \mathrm{C}$ and it is assumed to be fully functional at $25^{\circ} \mathrm{C}$ and lower. Hsps are of importance for heat resistance, and more generally for stress resistance, and have received widespread attention in the past decades (Feder \& Hofmann 1999, Sørensen et al. 2003). As such, Hsps are natural candidates for a genetic mechanism underlying the ability to sustain locomotor activity in thermally stressful environments. We hypothesize that $\mathrm{Hsf}^{+}$flies are able to remain active for a longer period at stressful temperatures than $\mathrm{Hsf}^{0}$ flies, since the latter line is not able to induce Hsps at high temperatures. Several experiments have shown recently that intrapopulation variation in Hsps explains only a minor proportion of thermal stress resistance, and suggests that many other mechanisms are involved (Jensen et al. 2010 and references therein, Bahrndorff et al. 2010, this Special). This may not be all that surprising given that most fitness-related traits are of a quantitative nature (Lynch 1996). In fact, flies adapted to hot environmental conditions often show reduced levels of heat-inducible Hsp70 compared to flies adapted to colder climates because of alterations in other phenotypic traits associated with heat resistance (e.g. Sørensen et al. 2001). We therefore also measured locomotor activity of $D$. melanogaster flies selected for increased HS or CS resistance. We expected the heat-resistant flies to remain active at higher temperatures than the cold-resistant flies.

\section{MATERIALS AND METHODS}

\subsection{Experimental flies}

The Hsf mutant flies of Drosophila melanogaster were originally created by Jedlicka et al. (1997) and obtained from the Bloomington Stock Center. One line $\left(\mathrm{Hsf}^{0}\right.$; stock no. 5489) is a heat-sensitive mutant line where the transcription factor of the heat shock genes (Hsf) goes from being fully functional at temperatures below $25^{\circ} \mathrm{C}$ to being non-functional at temperatures above $30^{\circ} \mathrm{C}\left(\mathrm{Hsf}^{4}\right.$ in Jedlicka et al. 1997). This line has a very limited induction of Hsps at temperatures above $30^{\circ} \mathrm{C}$ (Nielsen et al. 2005) because of a mutation (V57 $\mathrm{M})$ in the hsf gene. The other line ( $\mathrm{Hsf}^{+}{ }^{+}$stock no. 5490) was derived from the Hsf heat-sensitive line but has a functional hsf gene inserted, making these flies able to induce Hsps upon heat shock exposure. The insertion is maintained against a balancer chromosome and, therefore, the genetic background of the lines is slightly different for the third chromosome (see Jedlicka et al. 1997 for details). 
In addition to these lines we used 2 selection lines, HS and CS, which have been selected for increased heat or cold shock resistance, respectively, every other generation with 21 selection events. The 2 lines are highly differentiated for their ability to tolerate stressful high and low temperatures (HS3 and CS4 in Bubliy \& Loeschcke 2005, see this article for further details on selection procedures and responses). After selection, the flies were kept in standard laboratory conditions at high effective population sizes in order to reduce drift. Prior to the experiments, all flies were maintained in standard laboratory conditions at $25^{\circ} \mathrm{C}$ on agar, sugar, yeast and oatmeal medium under a $12 \mathrm{~h}$ light:12 h dark cycle. They were bred in $200 \mathrm{ml}$ culture bottles with $36 \mathrm{ml}$ of medium and 25 pairs per bottle, laying eggs for $24 \mathrm{~h}$.

\subsection{Experimental protocol}

For both experiments, newly hatched flies ( 0 to $24 \mathrm{~h}$ old) were collected from the bottles and sexed under $\mathrm{CO}_{2}$ anaesthesia. Males were transferred to fresh vials every second day until the experiments were performed. Activity data were collected with the Drosophila Activity Monitoring System (TriKinetics). We used 3 units, each with 32 positions, so that a total of 96 flies could be monitored simultaneously. In the monitoring system, flies were kept individually in $6.5 \mathrm{~cm}$ long capillary glass vials with an external diameter of $0.5 \mathrm{~cm}$, which were positioned horizontally. One end of the capillary glass vials was sealed with Parafilm ${ }^{\circledR}$ and the other end was closed with a small cotton wool stopper to allow gas exchange.

In the first experiment, $4 \mathrm{~d}$ old $\mathrm{Hsf}^{+}$and $\mathrm{Hsf}^{0}$ male flies were loaded into individual capillary glass vials without anaesthesia. At each temperature, 48 males from each of the 2 lines were tested in the activity monitoring system. In the next experiment, $4 \mathrm{~d}$ old male flies from the HS and CS lines were loaded into the capillary glass vials without anaesthesia. In both experiments the glass vials were inserted randomly into the 3 monitoring units and flies were allowed to recover at $25^{\circ} \mathrm{C}$ for $2 \mathrm{~h}$. The monitoring units were then put into pre-heated incubators at $28,34,36$ and $38^{\circ} \mathrm{C}$. When putting the flies into the incubators, activity increases considerably due to the new environment (reactivity), but after $10 \mathrm{~min}$ the variances of the mean activity have been shown to stabilize and reach a plateau (data not shown). Activity measurements therefore started $10 \mathrm{~min}$ after the flies were put into the incubators. The photocells in the plates registered the number of times that each fly passed through the midpoint of the capillary glass vial. The activity was registered for $180 \mathrm{~min}$ and all experiments were conducted between 10:00 and 16:00 h.

\subsection{Statistical analysis}

Activity data were converted to binary data, where 0 represents no activity (no movements detected) during the $30 \mathrm{~s}$ interval and 1 represents activity (passing the centre of the capillary glass vial at least one time in the $30 \mathrm{~s}$ interval). For every temperature treatment and line we estimated 2 measures of activity: (1) total activity, which was obtained by summing the binary data for each individual over the whole time period of an activity monitoring experiment, and (2) activity over time, which was obtained by averaging all the binary data for all individuals within each $30 \mathrm{~s}$ time interval during a run.

We tested for differences in total activity within each temperature treatment with $t$-tests. The significance level was adjusted using standard Bonferroni correction for multiple comparisons (Rice 1989).

In order to compare activity over time between lines in each experiment, we obtained a linear function describing activity. For each line this was done by calculating the mean activity for each data interval. The mean activity for each data interval was then logtransformed and regressed against the log-transformed time. We tested for differences in activity through time by testing for differences between the slopes of the regression lines (Z-test; Zar 1999). The linear regression analysis was only applied to data for active flies, which were obtained by excluding all data from the time point where 3 consecutive zeros were observed (no activity observed within 90 s). Differences in slopes between lines indicate differences in the changes of average activity over time. The significance levels for all conducted tests were adjusted using Bonferroni corrections for multiple comparisons (Rice 1989).

All statistical analyses were performed using the software PAST (Hammer et al. 2001) and JMP 4.0 (SAS Institute 2000). Graphics were made using R (R Development Core Team 2009).

\section{RESULTS}

For the Hsf lines we found a significantly higher total activity for the $\mathrm{Hsf}^{0}$ line flies compared to the $\mathrm{Hsf}^{+}$line at 28 and $34^{\circ} \mathrm{C}$ (Table 1). At these temperatures, the activity of the $\mathrm{Hsf}^{+}$and $\mathrm{Hsf}^{0}$ flies did not approach zero, indicating that a proportion was still active at the finalization of the run. At 36 and $38^{\circ} \mathrm{C}$, we found the opposite, with a significantly higher total activity of the Hsf ${ }^{+}$ compared to $\mathrm{Hsf}^{0}$ line (Table 1) and activity approached or reached zero.

For the selection lines we found a significantly higher total activity within temperatures for the HS 
Table 1. Drosophila melanogaster. Pairwise comparisons of total activity between the Hsf lines within temperature treatment-mean (total number of counts of activity averaged over all flies) \pm SE. Significance is indicated following standard Bonferroni correction ( $\mathrm{k}=4$; Rice 1989); ${ }^{* *} \mathrm{p}<0.01$, ${ }^{* * *} \mathrm{p}<0.001$, ns: not significant

\begin{tabular}{|lcccccc|}
\hline $\begin{array}{l}\text { Temp. } \\
\left({ }^{\circ} \mathrm{C}\right)\end{array}$ & $\mathrm{n}$ & $\mathrm{Hsf}^{+}$ & $\mathrm{n}$ & $\mathrm{Hsf}^{0}$ & $t$ & $\mathrm{p}$ \\
\hline 28 & 48 & $88.6 \pm 8.2$ & 48 & $143.3 \pm 13.2$ & 3.52 & $\left(\mathrm{HSF}^{0}>\mathrm{HSF}^{+}\right)^{* *}$ \\
34 & 48 & $133.5 \pm 10.9$ & 48 & $222.9 \pm 9.3$ & 6.23 & $\left(\mathrm{HSF}^{0}>\mathrm{HSF}^{+}\right)^{* * *}$ \\
36 & 48 & $194.5 \pm 10.2$ & 48 & $173.8 \pm 7.6$ & 1.63 & $\mathrm{~ns}^{-*}$ \\
38 & 48 & $50.8 \pm 2.9$ & 48 & $40.1 \pm 1.9$ & 3.05 & $\left(\mathrm{HSF}^{+}>\mathrm{HSF}^{-}\right)^{* *}$ \\
\hline
\end{tabular}

Table 2. Drosophila melanogaster. Pairwise comparisons of total activity between the heat shock (HS) and cold shock (CS) selected lines within temperature treatment-mean (total number of counts of activity averaged over all flies) \pm SE. Significance is indicated following standard Bonferroni correction $(\mathrm{k}=4$; Rice 1989$) ;{ }^{*} \mathrm{p}<0.05,{ }^{* * *} \mathrm{p}<0.001$, ns: not significant

\begin{tabular}{|lcccccc|}
\hline $\begin{array}{l}\text { Temp. } \\
\left({ }^{\circ} \mathrm{C}\right)\end{array}$ & $\mathrm{n}$ & $\mathrm{HS}$ & $\mathrm{n}$ & $\mathrm{CS}$ & $t$ & $\mathrm{p}$ \\
\hline 28 & 31 & $119.8 \pm 14.9$ & 32 & $143.6 \pm 18.2$ & 1.00 & $\mathrm{~ns}$ \\
34 & 32 & $221.0 \pm 13.0$ & 32 & $206.1 \pm 9.4$ & 4.87 & $(\mathrm{HS}>\mathrm{CS})^{* * *}$ \\
36 & 30 & $110.5 \pm 5.5$ & 32 & $93.0 \pm 5.4$ & 2.80 & $(\mathrm{HS}>\mathrm{CS})^{*}$ \\
38 & 32 & $43.3 \pm 1.7$ & 32 & $39.0 \pm 2.0$ & 1.68 & $\mathrm{~ns}$ \\
\hline
\end{tabular}

line when compared to the CS line at 34 and $36^{\circ} \mathrm{C}$ (Table 2). There were no differences between the lines at 28 and $38^{\circ} \mathrm{C}$.

The activity of the $\mathrm{Hsf}^{0}$ flies decreased faster than the activity of $\mathrm{Hsf}^{+}$flies at the 2 highest temperatures (Table 3, Fig. 1). This is demonstrated by a significantly less negative slope of the log average activity data against the log of time for the $\mathrm{Hsf}^{+}$line compared to $\mathrm{Hsf}^{0}$ line at $38^{\circ} \mathrm{C}$ (Table 3, top). At $36^{\circ} \mathrm{C}$, the difference was near significant $(p<0.1)$. There were no differences at the lower temperatures.

At $28^{\circ} \mathrm{C}$, the average activity over time of the $\mathrm{CS}$ and HS selection lines did not approach zero. The CS line increased while the HS line decreased slightly and both had a marked drop in activity level halfway. At $34^{\circ} \mathrm{C}$, the decrease in activity of the HS line was significantly slower with time when compared to the CS line (Table 3 , bottom). There were no differences in the decrease in activity over time at the 2 highest temperatures. The selection lines were generally less heat-resistant than the Hsf lines judging from the declines to zero activity (Fig. 1).
Table 3. Drosophila melanogaster. Pairwise test (Z-test) for differences between slopes of the linear regression (top) of $\log$ (mean activity data) versus $\log$ (time) between the Hsf lines within temperature treatments, and (bottom) log(mean activity data) versus $\log$ (time) between the heat shock (HS) and cold shock (CS) selected lines within temperature treatments. The functions and the lower and upper limits of the $95 \%$ confidence interval (CI) of the slopes are presented. Significance level is after Bonferroni correction $\left(\mathrm{k}=4\right.$; Rice 1989) ${ }^{*} \mathrm{p}<0.05,{ }^{* *} \mathrm{p}<0.01,{ }^{* * *} \mathrm{p}<0.001$, ns: not significant

\begin{tabular}{|c|c|c|c|c|c|c|}
\hline \multirow{2}{*}{$\begin{array}{l}\text { Temp. } \\
\left({ }^{\circ} \mathrm{C}\right)\end{array}$} & \multirow{2}{*}{ Line } & \multirow[t]{2}{*}{ Function } & \multirow[t]{2}{*}{$r^{2}$} & \multicolumn{2}{|c|}{$-95 \%$ CI of slope -} & \multirow[t]{2}{*}{$\mathrm{p}$} \\
\hline & & & & Lower limit & Upper limit & \\
\hline 28 & $\begin{array}{l}\mathrm{Hsf}^{+} \\
\mathrm{Hsf}^{0}\end{array}$ & $\begin{array}{l}y=-0.10 x+0.27 \\
y=-0.09 x+0.32\end{array}$ & $\begin{array}{l}0.58 \\
0.54\end{array}$ & $\begin{array}{l}-0.10 \\
-0.10\end{array}$ & $\begin{array}{l}-0.09 \\
-0.09\end{array}$ & ns \\
\hline 34 & $\begin{array}{l}\mathrm{Hsf}^{+} \\
\mathrm{Hsf}^{0}\end{array}$ & $\begin{array}{l}y=-0.19 x+0.49 \\
y=-0.17 x+0.53\end{array}$ & $\begin{array}{l}0.84 \\
0.72\end{array}$ & $\begin{array}{l}-0.194 \\
-0.181\end{array}$ & $\begin{array}{l}-0.18 \\
-0.16\end{array}$ & ns \\
\hline 36 & $\begin{array}{l}\mathrm{Hsf}^{+} \\
\mathrm{Hsf}^{0}\end{array}$ & $\begin{array}{l}y=-0.28 x+0.71 \\
y=-0.35 x+0.85\end{array}$ & $\begin{array}{l}0.82 \\
0.80\end{array}$ & $\begin{array}{l}-0.289 \\
-0.370\end{array}$ & $\begin{array}{l}-0.26 \\
-0.33\end{array}$ & $\left(\mathrm{HSF}^{+}>\mathrm{HSF}^{0}\right)^{* *}$ \\
\hline 38 & $\begin{array}{l}\mathrm{Hsf}^{+} \\
\mathrm{Hsf}^{0}\end{array}$ & $\begin{array}{l}y=-0.68 x+1.23 \\
y=-1.00 x+1.67\end{array}$ & $\begin{array}{l}0.95 \\
0.94\end{array}$ & $\begin{array}{l}-0.713 \\
-1.078\end{array}$ & $\begin{array}{l}-0.65 \\
-0.93\end{array}$ & $\left(\mathrm{HSF}^{+}>\mathrm{HSF}^{0}\right)^{*}$ \\
\hline 28 & $\begin{array}{l}\mathrm{HS} \\
\mathrm{CS}\end{array}$ & $\begin{array}{l}y=0.11 x-0.08 \\
y=0.04 x+0.08\end{array}$ & $\begin{array}{l}0.06 \\
0.11\end{array}$ & $\begin{array}{l}0.02 \\
0.02\end{array}$ & $\begin{array}{l}0.04 \\
0.05\end{array}$ & $(\mathrm{HS}>\mathrm{CS})^{* * *}$ \\
\hline 34 & $\begin{array}{l}\mathrm{HS} \\
\mathrm{CS}\end{array}$ & $\begin{array}{l}y=-0.22 x+0.62 \\
y=-0.31 x+0.74\end{array}$ & $\begin{array}{l}0.59 \\
0.64\end{array}$ & $\begin{array}{l}-0.25 \\
-0.35\end{array}$ & $\begin{array}{l}-0.20 \\
-0.27\end{array}$ & $(\mathrm{HS}>\mathrm{CS})^{* * *}$ \\
\hline 36 & $\begin{array}{l}\mathrm{HS} \\
\mathrm{CS}\end{array}$ & $\begin{array}{l}y=-0.31 x+0.71 \\
y=-0.37 x+0.79\end{array}$ & $\begin{array}{l}0.66 \\
0.74\end{array}$ & $\begin{array}{l}-0.36 \\
-0.42\end{array}$ & $\begin{array}{l}-0.28 \\
-0.33\end{array}$ & ns \\
\hline 38 & $\begin{array}{l}\mathrm{HS} \\
\mathrm{CS}\end{array}$ & $\begin{array}{l}y=-0.57 x+0.99 \\
y=-0.57 x+0.97\end{array}$ & $\begin{array}{l}0.82 \\
0.86\end{array}$ & $\begin{array}{l}-0.65 \\
-0.64\end{array}$ & $\begin{array}{l}-0.52 \\
-0.53\end{array}$ & ns \\
\hline
\end{tabular}

\section{DISCUSSION}

We predicted that the $\mathrm{Hsf}^{+}$ and HS lines would sustain activity longer than their counterparts; the $\mathrm{Hsf}^{+}$line because of its capacity to induce Hsps above $30^{\circ} \mathrm{C}$, in contrast to the $\mathrm{Hsf}^{0}$ line, and the HS line because of selection for increased heat resistance. This was observed in both pairs of lines. For the Hsf lines it occurred at the highest experimental temperature, whereas it occurred at the intermediate temperatures in the selection lines, which were generally less heat-resistant when comparing declines in activity over time (Fig. 1).

The predictions assume that staying active is indeed advantageous. It could also be hypothesized that it is better to discontinue activities and focus 

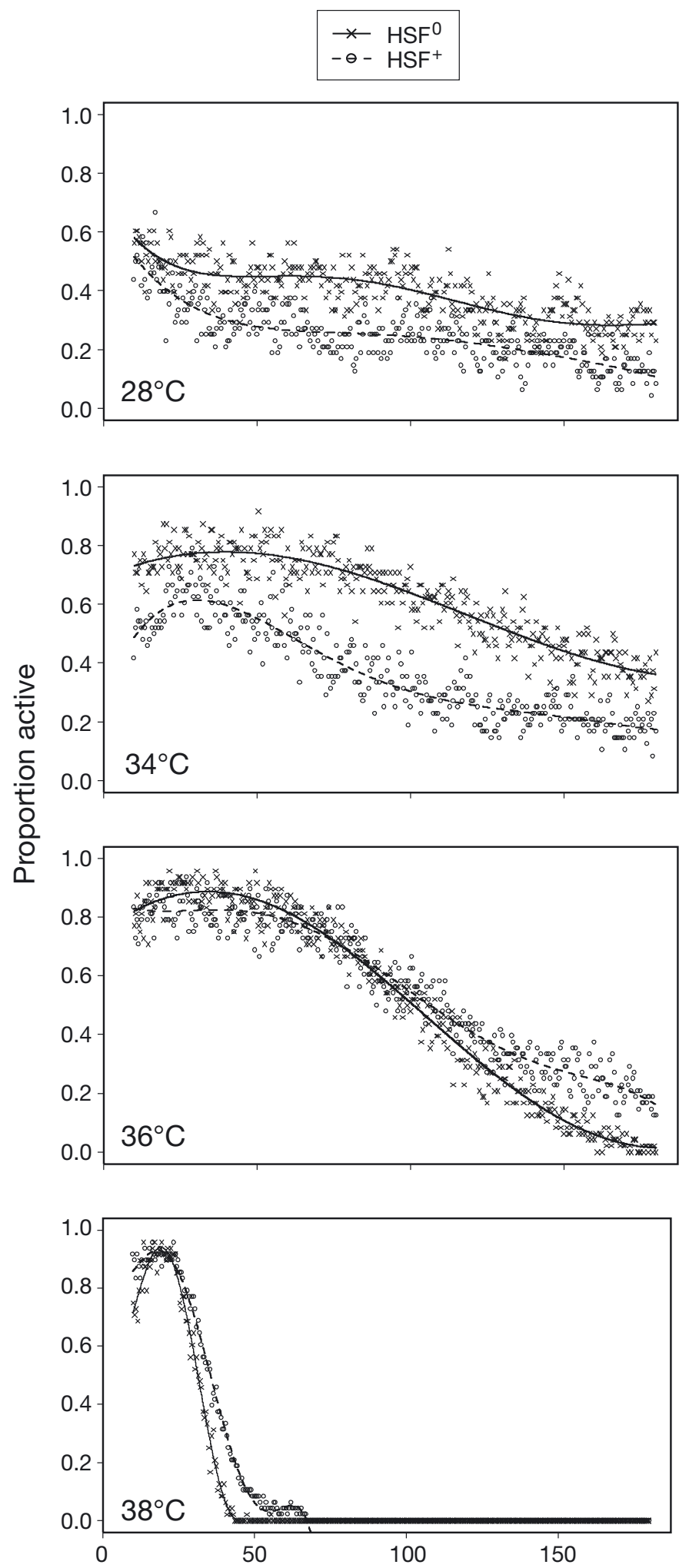
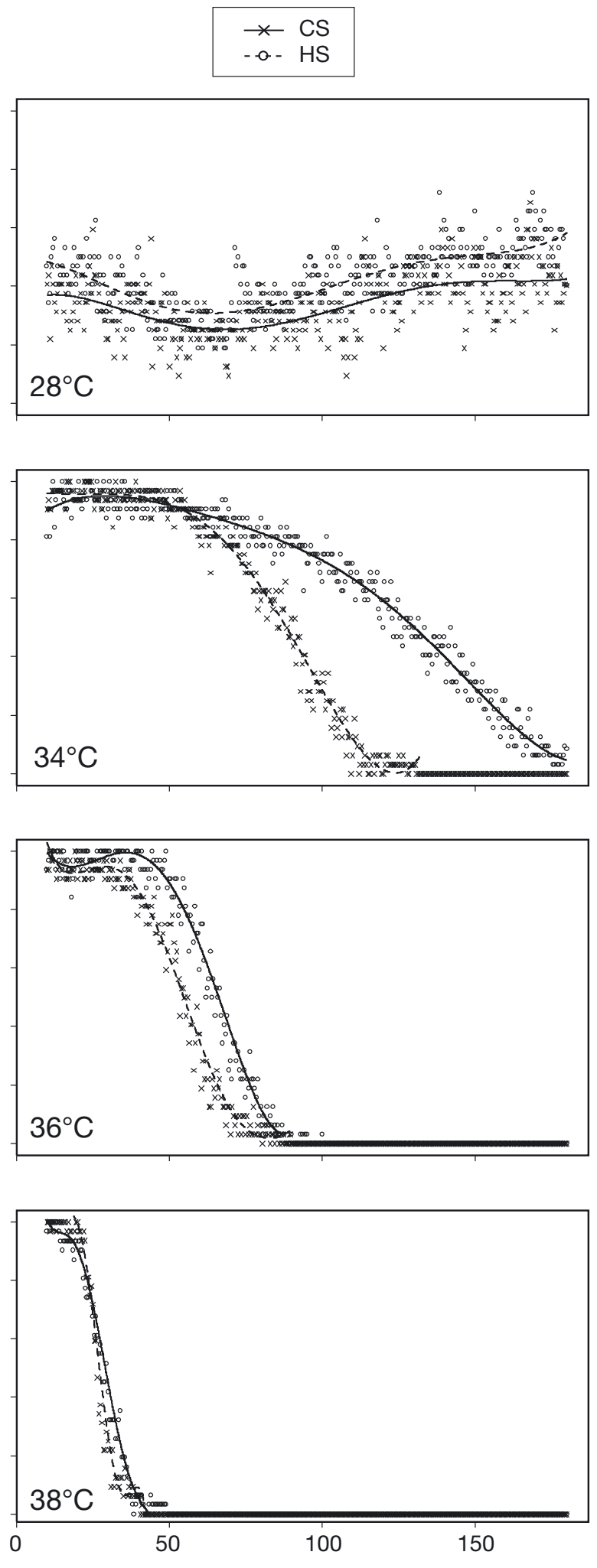

Time in minutes

Fig. 1. Drosophila melanogaster. Activity over time at 28, 34, 36 and $38^{\circ} \mathrm{C}$ for the $\mathrm{Hsf}^{+}$and $\mathrm{Hsf}^{0}$ lines (left) and cold shock (CS) and heat shock (HS) selected lines (right). The regression line is fitted to the data by polynomial regression (5th order) 
on metabolic adjustments that increase resistance. This may, however, be a risky strategy when temperatures are unpredictable and potentially lethal, which is certainly true for the higher of the temperatures used here (Nielsen et al. 2005). We find it more likely that flies remain active as long as possible in an attempt to escape (behavioural avoidance) (Stevenson 1985). Still, very little is known about thermoregulatory behaviour of adult Drosophila melanogaster in nature and further experiments are needed to establish the relative importance of the alternatives.

Perhaps more important, sustained activity increases the time and energy that individuals can allocate to mating and searching for food before having to retreat to more benign thermal conditions (Fasolo \& Krebs 2004). Our data indicates that the ability to induce Hsps could be important in this respect. The same can be said for thermal adaptation more generally; however, the mechanism may be different for the flies selected for HS resistance because selection for this capacity does not necessarily imply an important role for inducible Hsps (Jensen et al. 2010). Moreover, the heat shock response has negative consequences on several fitness-related traits (Krebs \& Loeschcke 1994, Feder 1996) and it has been suggested that such tradeoffs could lead to relatively low selection intensities on heat resistance in natural populations (Hoffmann et al. 2003, Fasolo \& Krebs 2004). Therefore, the effects on fitness in natural populations are largely dependent on the temperature regimes that prevail. We must also bear in mind that, in the natural environment, other factors such as food availability, humidity and photoperiod may interact with temperature to alter behavioural traits (Taylor 1986).

Other studies have found temperature-related adaptive differences in behavioural traits associated with reproduction. For instance, Fasolo \& Krebs (2004) found species-specific maximal temperatures at which courtship behaviour and mating ceased for Drosophila melanogaster, D. simulans and D. mojavensis, and intraspecific comparisons also revealed substantial variation among strains of $D$. mojavensis. Populations of $D$. buzzatii from different thermal environments (highland versus lowland) have been shown to differ in their diurnal timing of oviposition activity (Dahlgaard et al. 2001), and the preferred oviposition temperature is genetically determined in populations of $D$. melanogaster inhabiting different thermal environments in close proximity to each other (Nevo et al. 1998).

In the selection lines, the difference in activity disappeared at the highest temperature and ceased after about $1 \mathrm{~h}$. A possible explanation for this could be that the exposure is so severe that any effect of thermal adaptation is effectively overridden by high thermal instability of the cells and membranes compromising the locomotor system and survival.

At the lower experimental temperatures it was the flies with low heat resistance that were most active (though not significant for the selection lines). This could be an indication that these flies are more stressed and are moving in order to get away from the stress source, at least at $34^{\circ} \mathrm{C}$. However, predictions may not hold as the temperature becomes less stressful because of the less urgent need to escape. Still, mating behaviour and fertility will likely be affected sooner than survival (Patton \& Krebs 2001, Fasolo \& Krebs 2004, Jørgensen et al. 2006) and, therefore, higher activity could be positively related to these behaviours. In the present study, however, this remains highly speculative because of the absence of mating opportunities. A way to address this question could be to test entire populations for activity using population activity monitors.

We investigated the effect of selection for HS and CS resistance and expression of Hsps at the adult stage, but it is also important to keep in mind its potential role in the less immobile pre-adult stages. The fact that Hsps and some other mechanisms involved in heat resistance are also upregulated in response to many other types of stress (Sørensen et al. 2003) further complicates matters. The fact that the Hsf lines are genetically modified may also limit their relevance for ecological studies. Previous tests have shown that they exhibit highly trait-specific performances both in the laboratory and in the field (Sørensen et al. 2009). Particularly noteworthy is the relatively poor performance of the Hsf lines in field releases compared to a control line, but in stimulated maze activity, a test more similar to the present study, this difference between the Hsf lines and the control was only seen at $25^{\circ} \mathrm{C}$ and not at $36^{\circ} \mathrm{C}$ (Sørensen et al. 2009).

Interpretation of the results of the present study should also be made bearing in mind that locomotor behaviour is likely to be produced by a cascade of processes. The complexity of this cascade is likely to increase with the complexity of the behaviour and the number of environmental variables involved. Higher activity also means higher capacity to adopt behavioural thermoregulation strategies such as microhabitat choice to minimize variance in operative body temperatures as well as higher capacity to disperse in search of a new food supply. However, higher activity also means higher metabolic rate and higher energy demands. Metabolic rates of poikilotherms tend to increase exponentially as a function of temperature and the accelerating form of these functions implies that poikilotherm metabolic rates will increase with increasing temperature (Sharpe \& DeMichele, 1977). Thus, if an increased metabolic 
rate is not accompanied by an increase in resource supply, the energetic budget of the population will become negative and contest or scramble competition will affect the average fitness of the population. Although we have interpreted the sustained activity of the flies at high temperatures as advantageous, knowledge of the temperature-specific metabolic rates of the individual lines is necessary to understand under what environmental conditions this is in fact the case.

Acknowledgements. This study has been partly supported by a Marie Curie Transfer of Knowledge Fellowship BIORESC of European Community's Sixth Framework Program (contract no. MTKD-CT-2005-029957). Furthermore, we wish to thank the ConGen Program and the Therm Adapt Program (funded by the European Science Foundation) for this opportunity to discuss and publish our results in connection to the workshop 'Evolutionary and physiological adaptation to climate-induced environmental changes' held in Białowieża, Poland, July 2009. Finally, we thank the Danish Natural Research Counciland the Danish Natural Science Research Council for financial support to C.P. (grant nos. 21-01-0526 and 21-03-0125).

\section{LITERATURE CITED}

Bahrndorff S, Loeschcke V, Pertoldi C, Beier C, Holmstrup M (2009) The rapid cold hardening response of Collembola is influenced by thermal variability of the habitat. Funct Ecol 23:340-347

Bahrndorff S, Mariën J, Loeschcke V, Ellers J (2010) Genetic variation in heat resistance and Hsp70 expression in inbred isofemale lines of the springtail Orchesella cincta. Clim Res 43:41-47

Bettencourt BR, Drohan BW, Ireland AT, Santhanam M, Smrtic MB, Sullivan EM (2009) Natural variation in Drosophila stressed locomotion meets or exceeds variation caused by Hsp70 mutation: analysis of behavior and performance. Behav Genet 39:306-320

Bubliy OA, Loeschcke V (2005) Correlated responses to selection for stress resistance and longevity in a laboratory population of Drosophila melanogaster. J Evol Biol 18: 789-803

Byars SG, Hoffmann AA (2009) Lack of strong local adaptation in the alpine forb Craspedia lamicola in southeastern Australia. Int J Plant Sci 170:906-917

Chown SL, Hoffmann AA, Kristensen TN, Angilletta MJ Jr, Stenseth NC, Pertoldi C (2010) Adapting to climate change: a perspective from evolutionary physiology. Clim Res 43:3-15

Cossins AR, Bowler K (1987) Temperature biology of animals. Chapman \& Hall, New York

> Dahlgaard J, Hasson E, Loeschcke V (2001) Behavioral differentiation in oviposition activity in Drosophila buzzatii from highland and lowland populations in argentina: Plasticity or thermal adaptation? Evolution 55:738-747

Dillon ME, Wang G, Garrity PA, Huey RB (2009) Thermal preference in Drosophila. J Therm Biol 34:109-119

> Dingemanse NJ, Kazem AJN, Réale D, Wright J (2010) Behavioural reaction norms: animal personality meets individual plasticity. Trends Ecol Evol 25:81-89

> Dukas R (2004) Evolutionary biology of animal cognition. Annu Rev Ecol Evol Syst 35:347-374
Fasolo AG, Krebs RA (2004) A comparison of behavioural change in Drosophila during exposure to thermal stress. Biol J Linn Soc 83:197-205

Feder ME (1996) Ecological and evolutionary physiology of stress proteins and the stress response: the Drosophila melanogaster model. In: Johnston IA, Bennett AF (eds) Phenotypic and evolutionary adaptation to temperature. Cambridge University Press, Cambridge, p 79-102

Feder ME, Hofmann GE (1999) Heat-shock proteins, molecular chaperones, and the stress response: evolutionary and ecological physiology. Annu Rev Physiol 61:243-282

- Fleury F, Vavre F, Ris N, Fouillet P, Bouletreau M (2000) Physiological cost induced by the maternally-transmitted endosymbiont wolbachia in the Drosophila parasitoid Leptopilina heterotoma. Parasitology 121:493-500

Gibert P, Huey RB, Gilchrist GW (2001) Locomotor performance of Drosophila melanogaster: interactions among developmental and adult temperatures, age, and geography. Evolution 55:205-209

Hammer $\varnothing$, Harper DAT, Ryan PD (2001) PAST: paleontological statistics software package for education and data analysis. Palaentol Electron 4:1-9

Hochachka PW, Somero GN (2002) Biochemical adaptation: mechanism and process in physiological evolution. Oxford University Press, New York

Hoffmann AA, Sørensen JG, Loeschcke V (2003) Adaptation of Drosophila to temperature extremes: bringing together quantitative and molecular approaches. J Therm Biol 28: $175-216$

> Huey RB, Hertz PE, Sinervo B (2003) Behavioral drive versus behavioral inertia in evolution: a null model approach. Am Nat 161:357-366

Jedlicka P, Mortin MA, Wu C (1997) Multiple functions of Drosophila heat shock transcription factor in vivo. EMBO J 16:2452-2462

Jensen LT, Cockerell FE, Kristensen TN, Rako L, Loeschcke V, McKechnie SW, Hoffmann AA (2010) Adult heat tolerance variation in Drosophila melanogaster is not related to Hsp70 expression. J Exp Zool Part A 313A:35-44

Jørgensen KT, Sørensen JG, Bundgaard J (2006) Heat tolerance and the effect of mild heat stress on reproductive characters in Drosophila buzzatii males. J Therm Biol 31: $280-286$

Kennedy AD (1997) Bridging the gap between general circulation model (GCM) output and biological microenvironments. Int J Biometeorol 40:119-122

Kingsolver JG, Ragland GJ, Diamond SE (2009) Evolution in a constant environment: thermal fluctuations and thermal sensitivity of laboratory and field populations of Manduca sexta. Evolution 63:537-541

Kjærsgaard A, Faurby S, Andersen DH, Pertoldi C, David JR, Loeschcke V (2007) Effects of temperature and maternal and grandmaternal age on wing shape in parthenogenetic Drosophila mercatorum. J Therm Biol 32:59-65

Krebs RA, Loeschcke V (1994) Costs and benefits of activation of the heat-shock response in Drosophila melanogaster. Funct Ecol 8:730-737

Lee JE, Janion C, Marais E, van Vuuren BJ, Chown SL (2009) Physiological tolerances account for range limits and abundance structure in an invasive slug. Proc R Soc Lond B 276:1459-1468

Lynch MM (1996) A quantitative genetic perspective on conservation issues. In: Avise JC, Hamrick JL (eds) Conservation genetics: case histories from nature. Chapman \& Hall, New York, p 471-501

Martin JR (2003) Locomotor activity: a complex behavioural trait to unravel. Behav Processes 64:145-160 
Nevo E, Rashkovetsky E, Pavlicek T, Korol A (1998) A complex adaptive syndrome in Drosophila caused by microclimatic contrasts. Heredity 80:9-16

Nielsen M, Overgaard J, Sørensen JG, Holmstrup M, Justesen J, Loeschcke V (2005) Role of HSF activation for resistance to heat, cold and high-temperature knock-down. J Insect Physiol 51:1320-1329

Patton ZJ, Krebs RA (2001) The effect of thermal stress on the mating behavior of three Drosophila species. Physiol Biochem Zool 74:783-788

R Development Core Team (2009) R version 2.11.0. Available at www.r-project.org/

Rego C, Balanya J, Fragata I, Matos M, Rezende EL, Santos M (2010) Clinal patterns of chromosomal inversion polymorphisms in Drosophila subobscura are partly associated with thermal preferences and heat stress resistance. Evolution 64:385-397

Rice WR (1989) Analyzing tables of statistical tests. Evolution 43:223-225

Roff DA (2002) Life history evolution. Sinauer Associates, Sunderland, MA

Ruel JJ, Ayres MP (1999) Jensen's inequality predicts effects of environmental variation. Trends Ecol Evol 14:361-366

SAS Institute (2000) JMP statistics and graphics guide, version 4. SAS Institute, Cary, NC

Submitted: April 6, 2010; Accepted: April 30, 2010
Sharpe PJH, DeMichele DW (1977) Reaction kinetics of poikilotherm development. J Theor Biol 64:649-670

Sørensen JG, Dahlgaard J, Loeschcke V (2001) Genetic variation in thermal tolerance among natural populations of Drosophila buzzatii: down regulation of Hsp70 expression and variation in heat stress resistance traits. Funct Ecol 15: 289-296

Sørensen JG, Kristensen TN, Loeschcke V (2003) The evolutionary and ecological role of heat shock proteins. Ecol Lett 6:1025-1037

Sørensen JG, Loeschcke V, Kristensen TN (2009) Lessons from the use of genetically modified Drosophila melanogaster in ecological studies: Hsf mutant lines show highly traitspecific performance in field and laboratory thermal assays. Funct Ecol 23:240-247

> Stevenson RD (1985) The relative importance of behavioral and physiological adjustments controlling body temperature in terrestrial ectotherms. Am Nat 126:362-386

Taylor CE (1986) Habitat choice by Drosophila pseudoobscura: the roles of genotype and of experience. Behav Genet 16:271-279

Valente D, Golani I, Mitra PP (2007) Analysis of the trajectory of Drosophila melanogaster in a circular open field arena. PLoS ONE 2:e1083

Zar JH (1999) Biostatistical analysis. Prentice Hall, New Jersey

Proofs received from author(s): June 7, 2010 